\title{
Papillary Meningioma: Case Presentation with Emphasis on Surgical and Medical Therapy of a Rare Variant of Meningioma
}

\author{
Gerardo Cazzato ${ }^{1, *},+\left(\mathbb{C}\right.$, Valeria Internò ${ }^{2,+}{ }^{\oplus}$, Antonietta Cimmino ${ }^{1}$, Raffaella Messina ${ }^{3}{ }^{(0}$, Marco Tucci ${ }^{2}{ }^{\circ}$, \\ Teresa Lettini ${ }^{1}{ }^{1}$, Leonardo Resta ${ }^{1,+}+\mathbb{D}$ and Giuseppe Ingravallo ${ }^{1, *,+} \mathbb{\infty}$ \\ 1 Section of Pathology, Department of Emergency and Organ Transplantation (DETO), University of Bari Aldo \\ Moro, 70124 Bari, Italy; micasucci@inwind.it (A.C.); lettinit@yahoo.com (T.L.); leonardo.resta@uniba.it (L.R.) \\ 2 Department of Biomedical Sciences and Human Oncology, University of Bari Aldo Moro, 70124 Bari, Italy; \\ valeria.interno@libero.it (V.I.); marco.tucci@uniba.it (M.T.) \\ 3 Neurosurgery Unit, Department of Basic Medical Science, Neurosciences and Sense Organs, "Aldo Moro" \\ University of Bari Medical School, 70124 Bari, Italy; raffaella.messina@uniba.it \\ * Correspondence: gerycazzato@hotmail.it (G.C.); giuseppe.ingravallo@uniba.it (G.I.); \\ Tel.: +39-340-5203641 (G.C.) \\ + Authors contributed to equal measure.
}

check for updates

Citation: Cazzato, G.; Internò, V.; Cimmino, A.; Messina, R.; Tucci, M.; Lettini, T.; Resta, L.; Ingravallo, G.

Papillary Meningioma: Case

Presentation with Emphasis on Surgical and Medical Therapy of a Rare Variant of Meningioma. Diseases 2021, 9, 63. https://doi.org/10.3390/ diseases 9030063

Academic Editor: Omar Cauli

Received: 19 July 2021

Accepted: 13 September 2021

Published: 17 September 2021

Publisher's Note: MDPI stays neutral with regard to jurisdictional claims in published maps and institutional affiliations.

Copyright: (c) 2021 by the authors. Licensee MDPI, Basel, Switzerland. This article is an open access article distributed under the terms and conditions of the Creative Commons Attribution (CC BY) license (https:/ / creativecommons.org/licenses/by/ $4.0 /)$.
Abstract: Meningioma is one of the most frequent neoplasms of all in the central nervous system. Different variants are known, and of these some have peculiar characteristics, both from a morphological point of view and from a biological point of view. Here, we present a rare case of relapsed papillary meningioma in a young patient, focusing on histological characteristics, medical-surgical therapy and focusing on the risk of progression and/or recurrence of the lesion if not completely eradicated. Finally, we provide detailed molecular characteristics of the case in question.

Keywords: papillary meningioma; neurosurgery; oncology; rare tumours

Meningiomas represent a group of slow-growing neoplasms that arise from the arachnoidal cap cells of the meninges [1,2]. The majority of meningiomas histologically correspond to grade I tumours, according to the 2016 World Health Organization (WHO) classification of the central nervous system [2]. In the literature, there are various histopathological variants of meningiomas, each one with a peculiar biological behaviour and, consequently, with a different clinical outcome [2,3]. Meningiomas are most frequently diagnosed in women and usually express progesterone receptors [1,3]. Among the different histopathological variants, papillary meningioma (PM) constitutes $<1 \%$ of all meningiomas and is classified as a rare variant, histologically corresponding to WHO grade III, known as malignant meningiomas [1-11].

Here, we present a case of papillary meningioma that arose in a 42-year-old woman and relapsed seven years after the first surgical removal and adjuvant radiation therapy. We then explored the available systemic strategies available in the existing literature.

In 2010, a 42-year-old woman reported a headache, speech difficulties and hypersomnia for about one week. After careful neurological consultation and the persistence of symptoms, we opted to perform a functional magnetic resonance imaging (MRI) with gadolinium, which revealed the presence of a neoplastic lesion in the left frontoparietal area. The patient underwent removal of the lesion (Simpson's grade 2 the boundary of the tumour was unclear and invaded the surrounding brain tissue) and the histopathological analysis revealed a PM. Then, due to the histopathological analysis and the residual tumour, a conformational radiotherapy adjuvant treatment was performed (60 Gy per fraction of 2 Gy in 30 sessions). The disease dd not reoccur until 2015, when a brain MRI with gadolinium documented disease recurrence in the same area of the previous surgical removal. The patient, again, underwent the neurosurgical removal of the lesion. She then decided to disregard the radiological follow-up. 
In November 2020, she reported again headache, sleep disturbances and functional symptoms. A brain MRI was performed (Figure 1A,B) and showed a giant meningioma in the left parietal area of $5 \times 5 \mathrm{~cm}$. The mass was surrounded by a perifocal oedema with consecutive compression and dislocation to the right of the ventricular system. The temporal horn of the ipsilateral ventricle resulted in communication with the subarachnoid space. The administration of the gadolinium determined inhomogeneous accentuation of the mass. The patient was again subjected to tumour excision, which was performed at the Neurosurgery department of the University Hospital of Bari. Table 1 summarizes the main steps of the patient.
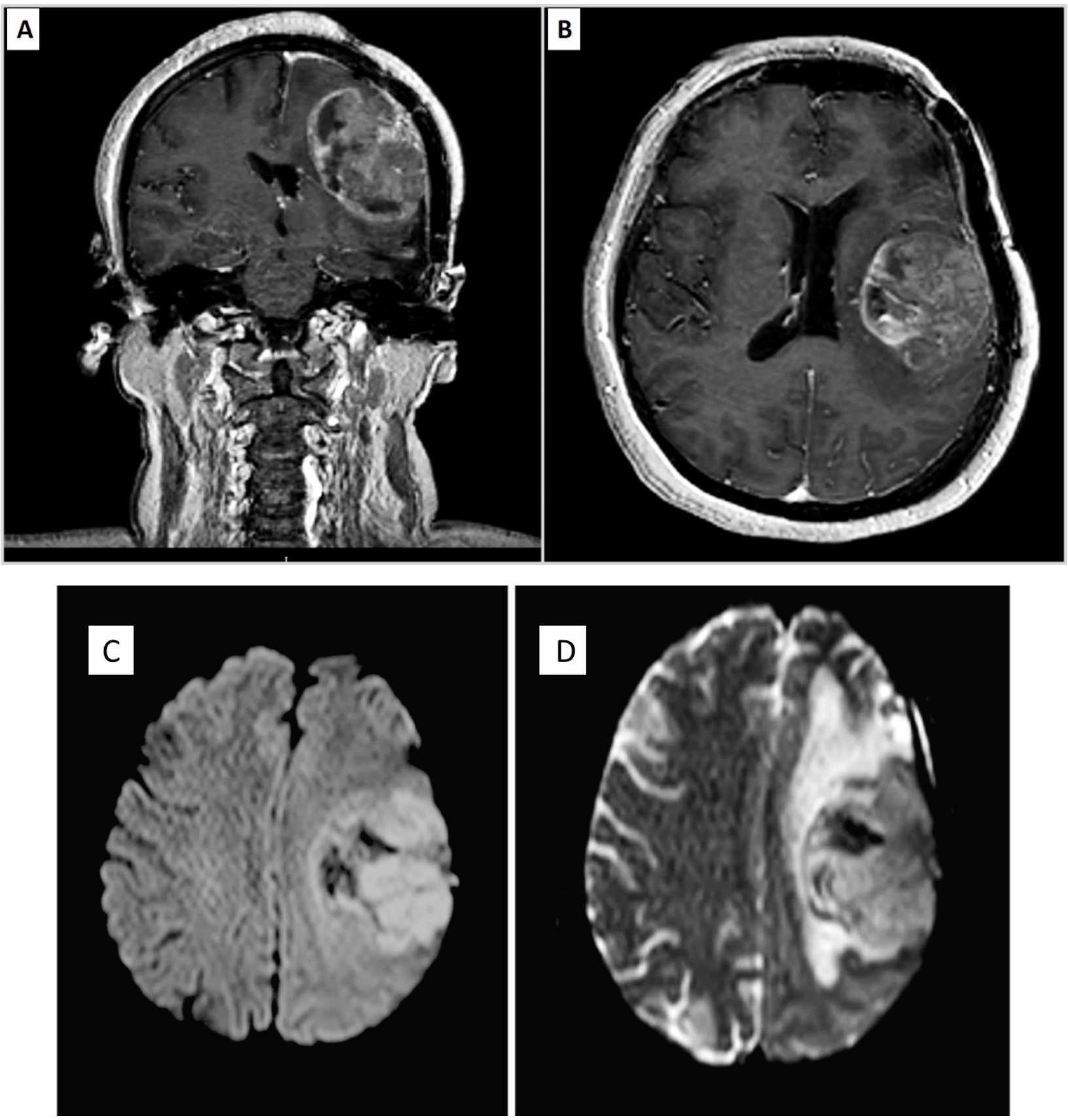

Figure 1. (A,B) Axial and coronal projections. Large meningioma in the left parietal area of $5 \times 5 \mathrm{~cm}$. The mass is surrounded by perifocal oedema with consecutive compression and dislocation to the right of the ventricular system. The temporal horn of the ipsilateral ventricle results in communication with the subarachnoid space. The administration of the gadolinium determines inhomogeneous accentuation of the mass. (C,D) PM displays an heterogenous hyperintensity in DWI surrounded by an hypointense oedema. 
Table 1. Summary of the patient's medical history mentioning symptoms, diagnosis, and therapeutic treatment.

\begin{tabular}{cccc}
\hline Years & Symptoms & Diagnosis & Treatment \\
\hline 2010 & $\begin{array}{c}\text { Headache, speech } \\
\text { difficulties and } \\
\text { hypersomnia }\end{array}$ & $\begin{array}{c}\text { Neoplastic lesion in the left } \\
\text { frontparietal area compatible } \\
\text { with papillary meningioma }\end{array}$ & $\begin{array}{c}\text { Surgical removal and } \\
\text { radiotherapy } \\
\text { adjuvant treatment }\end{array}$ \\
\hline 2015 & Headache & Recurrence of PM & $\begin{array}{c}\text { Neurosurgical } \\
\text { removal }\end{array}$ \\
\hline & $\begin{array}{c}\text { Headache, sleep } \\
\text { disturbances and } \\
\text { functional symptoms }\end{array}$ & Recurrence of PM & Tumour excision \\
\hline
\end{tabular}

The lesion was fixed in 10\% buffered formaldehyde and sent to our pathology laboratory. After sampling, processing, paraffin embedding and microtome cutting, five-micron thick sections were obtained and stained with Haematoxylin Eosin for observation under an optical microscope. The presence of a proliferation, characterized by pseudopapillary architecture with loss of cellular cohesion, clinging of tumour cells in blood vessels and the presence of nucleus-free perivascular zones that resembled the ependymoma pseudorosette was demonstrated (Figure 2A-C). Immunohistochemically, there was a strong expression of Epithelial Membrane Antigen (EMA, Figure 2D) and Vimentin (not shown), while the progesterone receptor (PR) was focally positive $(<10 \%)$, as is usual in anaplastic meningiomas that do not usually have a positive expression of PR. The neoplastic proliferation fraction (Ki67+) was $>20 \%$. In consideration of the histological and immunophenotypic picture, the diagnosis of papillary meningioma, grade III (WHO) was made. The patient then refused any other type of adjuvant treatment and was lost at follow-up.

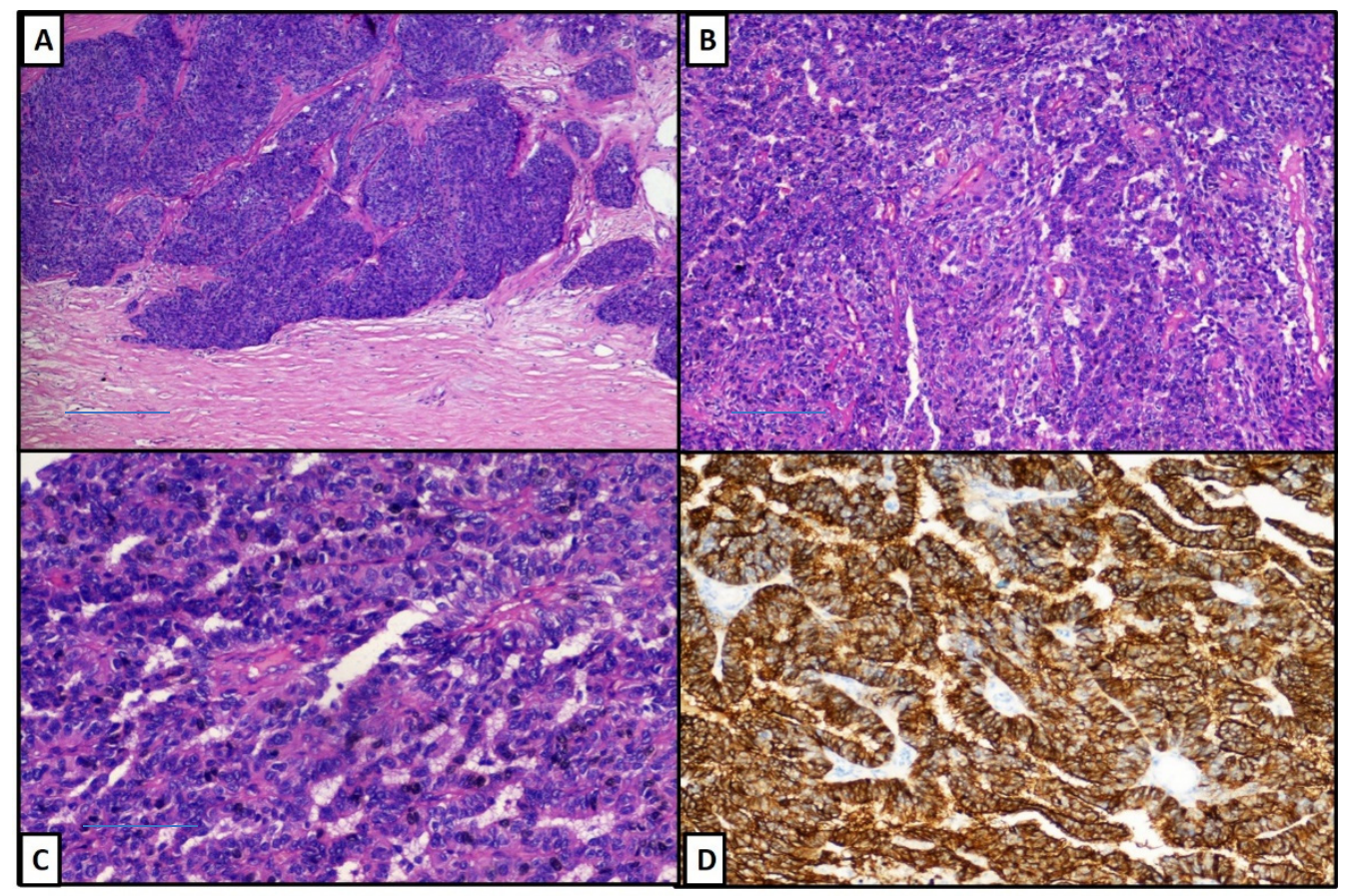

Figure 2. (A-C) The presence of a proliferation characterized by pseudopapillary architecture, with loss of cellular cohesion, clinging of tumour cells in blood vessels and the presence of nucleus-free perivascular zones that resembled the ependymoma pseudo-rosette was demonstrated. (Haematoxylin-Eosin, Original Magnification: $10 \times, 20 \times$ and $40 \times$, respectively). (D) Immunohistochemically, there was a strong expression of Epithelial Membrane Antigen (EMA, immunohistochemistry, original magnification: $20 \times$ ). 
From a molecular point of view, cytogenetic investigations were carried out, which revealed very interesting and suggestive results; in particular, a characteristic codeletion of chromosomes $1 p$ and $14 q$ was found, the realization of which has recently been suggested as a potential adverse prognostic risk factor in meningioma [12]. There were no NF2 mutations [13], but there were two copy number losses of the PBRM1 gene [14]. There were no other mutations in other genes, such as BAP1 or others.

Regarding therapeutic systemic strategies for recurrent PM, a rare but aggressive variant as demonstrated in this case report, there is a lack of universally accepted guidelines after re-surgery and re-irradiation therapy [15]. Regarding prognostic factors, the impact of the extent of surgical resection is well-known, otherwise, postoperative radiation therapy on survival of PM patients has not been well studied due to the limited number of cases of PM. However, Simpson grading prognostic score is accepted and individuates four different subgroups (grade I to IV) based on residual tumour or infiltrated dura. In particular, residual tumour tissue after surgery or infiltrated dura result in a significant risk of tumour recurrence. Moreover, it remains unclear if the prognostic role of Simpson grading stands nowadays, especially with regard to the adjuvant radiotherapy for selected cases of subtotal resections (Simpson grade IV) that are associated with higher risk for tumour recurrence [16]. Furthermore, Simpson grade I-III (no or minimal residual disease) vs. grade $\geq$ IV (macroscopic residual disease) resections allow a more exact prediction of the risk of postoperative tumour relapse [17]. A recent published analysis of 108 patients with papillary meningioma identifies EOR as an important prognostic factor, even in multivariate analysis. To date, patients who underwent gross total resection (GTR) had a significantly higher probability of disease-specific survival compared with those who underwent subtotal resection (STR). Concerning the presumed prognostic significance of the progesterone receptor expression detectable by immunohistochemistry, a recent work by Hua L. et al. [18] did not identify a relationship between expression and patient outcome, unlike the immunoexpression of the oestrogen receptor.

Regarding post-operative management, adjuvant radiotherapy is associated with DSS in univariate analysis. As a result, GTR resulted in a 5-year PFS rate of 36.7\% compared with $0 \%$ in the case of STR. Sumner et al. explored the survival benefit of postoperative radiation therapy in PM and demonstrated improved survival, arguing for postoperative radiation therapy to manage those aggressive tumours [19]. As a result, despite the lack of prospective studies, postoperative radiotherapy represents the standard of care. Another possible option for post-operative treatment is represented by the proton therapy. This type of radiotherapy allows the total dose to be increased and provides the greatest coverage of the target volume, while not being limited by the large size or abnormal shape of the target tumour.

Regarding systemic adjuvant strategies, chemotherapy has failed in controlling malignant meningioma growth and has only been investigated in small clinical trials given the paucity of this tumour type. Established chemotherapeutic agents in the treatment of other systemic tumours have not replicated their robust activity in controlling malignant meningioma growth. In particular, hydroxyurea, an oral ribonucleotide reductase inhibitor, halts meningioma cell growth, the S-phase of the cell cycle, and induces apoptosis. One preliminary report found that hydroxyurea prevented recurrent growth for 24 months in a patient following GTR of a malignant meningioma [20]. In addition, a prospective study of 16 patients with recurrent meningiomas, five of whom were classified as grade III, studied the effect of a somatostatin analogue on radiographic response and progression-free survival at six months. These tumours were shown to overexpress somatostatin receptors by octreotide scintigraphy and so were considered responsive to a long-acting somatostatin analogue. Only one of the five Grade III meningiomas demonstrated a partial response to the treatment, while another Grade III patient showed stable disease with the remaining three showing progressive disease $[19,20]$. In the case of recurrent malignant meningiomas, there is a less codified approach. The early consensus is repeat surgery, but the role of adjuvant therapies such as radiation and chemotherapy are less convincing [15]. 
Papillary meningioma is a rare variant of meningioma, defined by the presence of a perivascular pseudopapillary pattern constituting most of the tumour [1,5], and it is considered as WHO grade III (malignant meningioma) [1]. Histologically, pseudo-papillary architecture is characterized by loss of cohesion, with the presence of pseudo-rosettes resembling ependymoma [1,2] with occasional foci of necrosis. Immunostaining for EMA and Vimentin are, frequently, strongly positive, with different and wide expressions of Progesterone Receptor and Ki67+ which is usually around 5-6\% [4,5]. Some meningiomas combine a papillary architecture with rhabdoid cytology and this finding was correlated with an even more aggressive clinical-biological behaviour [6,7]. Generally, papillary meningiomas have an invasive tendency, including brain invasion [1,6], recurrence and metastasis $[1,7,8]$. It is important to underline that other meningioma subtypes can also exhibit a papillary pattern, but that the histological diagnosis of PM should only be made when almost the entire mass has this type of histological pattern [1,7]. Furthermore, given the high incidence of being faced with the possibility of an impromptu, it can be very difficult to discriminate this type of meningioma from high-grade glial lesions [9]. Recently, some authors as Cheng and Al. described intra-tumoral cystic changes in PM without correlating with the increased aggression of biological behaviours [10] and, above all, once recurred and re-irradiated, no systemic treatment strategies are known to be efficacious in controlling the tumour growth.

Finally, we have reported our experience with a rare case of papillary meningioma that has recurred twice, and we discussed the various steps for a correct medical-surgical management of this entity. Future directions will go towards a greater understanding of the etiopathogenesis of the lesion and, possibly, the development of drugs able to reduce the recurrence of this aggressive subtype of meningioma.

Author Contributions: Conceptualization, G.C. and V.I.; methodology, G.C.; software, R.M.; validation, M.T., R.M. and G.I.; formal analysis, L.R.; investigation, G.C.; resources, T.L.; data curation, A.C.; writing—original draft preparation, G.C.; writing—review and editing, G.C., V.I., M.T., R.M. and G.I.; visualization, G.C.; supervision, M.T. All authors have read and agreed to the published version of the manuscript.

Funding: This research received no external funding.

Institutional Review Board Statement: Not applicable as it is not a systematic study but a finding during daily routine diagnostic activities.

Informed Consent Statement: Informed consent was obtained from all subjects involved in the study.

Data Availability Statement: Not applicable.

Conflicts of Interest: The authors declare no conflict of interest.

\section{References}

1. WHO. Classification of Tumours of the Central Nervous System; World Health Organization: Lyon, France, 2016.

2. Buerki, R.A.; Horbinski, C.M.; Kruser, T.; Horowitz, P.M.; James, C.D.; Lukas, R.V. An overview of meningiomas. Future Oncol. 2018, 14, 2161-2177. [CrossRef] [PubMed]

3. Preusser, M.; Brastianos, P.K.; Mawrin, C. Advances in meningioma genetics: Novel therapeutic opportunities. Nat. Rev. Neurol. 2018, 14, 106-115. [CrossRef] [PubMed]

4. Wiemels, J.; Wrensch, M.; Claus, E.B. Epidemiology and etiology of meningioma. J. Neurooncol. 2010, 99, 307-314. [CrossRef] [PubMed]

5. Stefanko, S.Z.; Mackay, W.M. Papillary meningioma. Acta Neuropathol. 1981, 7, 126-128.

6. Ludwin, S.K.; Rubinstein, L.J.; Russell, D.S. Papillary meningioma: A malignant variant of meningioma. Cancer 1975, 36, 1363-1373. [CrossRef]

7. Wu, Y.T.; Ho, J.T.; Lin, Y.J.; Lin, J.W. Rhabdoid papillary meningioma: A clinicopathologic case series study. Neuropathology 2011, 31, 599-605. [CrossRef] [PubMed]

8. Kros, J.M.; Cella, F.; Bakker, S.L.; Paz, Y.; Geuze, D.; Egeler, R.M. Papillary meningioma with pleural metastasis: Case report and literature review. Acta Neurol. Scand. 2000, 102, 200-202. [CrossRef] [PubMed]

9. Tathe, S.P.; Parate, S.N. Papillary meningioma: Diagnosis by intraoperative crush smear cytology. Diagn. Cytopathol. 2019, 47, 907-911. [CrossRef] [PubMed] 
10. Cheng, Z.; Chao, Q.; Zhang, H.; Wang, D.W.; Shu, H.S. Intraventricular cystic papillary meningioma: A case report and literature review. Medicine 2020, 99, e21514. [CrossRef] [PubMed]

11. Jiang, X.B.; Ke, C.; Han, Z.A.; Lin, S.H.; Mou, Y.G.; Luo, R.Z.; Wu, S.X.; Chen, Z.P. Intraparenchymal papillary meningioma of brainstem: Case report and literature review. World J. Surg. Oncol. 2012, 12, 10. [CrossRef] [PubMed]

12. Lee, Y.S.; Lee, Y.S. Molecular characteristics of meningiomas. J. Pathol. Transl. Med. 2020, 54, 45-63. [CrossRef] [PubMed]

13. Hartmann, C.; Sieberns, J.; Gehlhaar, C.; Simon, M.; Paulus, W.; von Deimling, A. NF2 mutations in secretory and other rare variants of meningiomas. Brain Pathol. 2006, 16, 15-19. [CrossRef] [PubMed]

14. Williams, E.A.; Wakimoto, H.; Shankar, G.M.; Barker, F.G., 2nd; Brastianos, P.K.; Santagata, S.; Sokol, E.S.; Pavlick, D.C.; Shah, N.; Reddy, A.; et al. Frequent inactivating mutations of the PBAF complex gene PBRM1 in meningioma with papillary features. Acta Neuropathol. 2020, 140, 89-93. [CrossRef] [PubMed]

15. Behling, F.; Fodi, C.; Hoffmann, E.; Renovanz, M.; Skardelly, M.; Tabatabai, G.; Schittenhelm, J.; Honegger, J.; Tatagiba, M. The role of Simpson grading in meningiomas after integration of the updated WHO classification and adjuvant radiotherapy. Neurosurg. Rev. 2020, 44, 2329-2336. [CrossRef] [PubMed]

16. Brokinkel, B.; Spille, D.C.; Brokinkel, C.; Hess, K.; Paulus, W.; Bormann, E.; Stummer, W. The Simpson grading: Defining the optimal threshold for gross total resection in meningioma surgery. Neurosurg. Rev. 2020, 41, 1713-1720. [CrossRef] [PubMed]

17. Sumner, W.A.; Amini, A.; Hankinson, T.C.; Foreman, N.K.; Gaspar, L.E.; Kavanagh, B.D.; Karam, S.D.; Rusthoven, C.G.; Liu, A.K. Survival benefit of postoperative radiation in papillarymeningioma: Analysis of the National Cancer Data Base. Rep. Pract. Oncol. Radiother. 2017, 22, 495-501. [CrossRef] [PubMed]

18. Hua, L.; Zhu, H.; Li, J.; Tang, H.; Kuang, D.; Wang, Y.; Tang, F.; Chen, X.; Zhou, L.; Xie, Q.; et al. Prognostic value of estrogen receptor in WHO Grade III meningioma: A long-term follow-up study from a single institution. J. Neurosurg. 2018, 128, 1698-1706. [CrossRef]

19. Pellerino, A.; Bruno, F.; Internò, V.; Rudà, R.; Soffietti, R. Current clinical management of elderly patients with glioma. Expert Rev. Anticancer Ther. 2020, 20, 1037-1048. [CrossRef] [PubMed]

20. Chamberlain, M.C.; Glantz, M.J.; Fadul, C.E. Recurrent meningioma: Salvage therapy with long-acting somatostatin analogue. Neurology 2007, 69, 969-973. [CrossRef] 